\title{
Crystallographic Characterization of Flavodoxin from Anacystis nidulans
}

\begin{abstract}
Flavodoxin isolated from the blue-green alga, Anacystis nidulans, crystallizes from ammonium sulfate in space group $P 2_{1} 2_{1} 2_{1}$, with $a=57 \cdot 08 \AA, b=69 \cdot 24 \AA$ and $c=45.55 \AA$. The diffraction patterns extend to a resolution of at least $1.8 \AA$. Reduction of the flavin mononucleotide in the crystalline protein, to either the semi-quinone or fully reduced (hydroquinone) state, results in minimal changes in cell dimensions and diffracted intensities. The higher molecular weight $(19,000$ to 20,000 ) and spectral properties of the A. nidulans protein, along with the near-isomorphism of crystals of the three oxidation states, distinguish this crystalline flavodoxin from the corresponding proteins of Clostridium $M P$ and Desulfovibrio vulgaris, whose three-dimensional structures are known. In contrast to Clostridium flavodoxins, but like the $D$. vulgaris protein, $A$. nidulans flavodoxin is capable of binding riboflavin in place of flavin mononucleotide $\left(K_{\mathrm{a}}=2 \times 10^{8} \mathrm{M}^{-1}\right)$.
\end{abstract}

The flavodoxins are a group of microbial proteins that supplant or supplement plant and bacterial ferredoxins in a variety of electron transfer reactions. The first of these flavin mononucleotide-containing proteins to be purified was isolated from the bluegreen alga, Anacystis nidulans, by Smillie $(1963,1965)$ who showed that it could replace ferredoxin in the light-dependent reduction of $\mathrm{NADP}^{+}$by chloroplasts. Subsequently flavodoxins have been found in at least a dozen organisms (Yoch \& Valentine, 1972) and a number of physical and chemical studies of these proteins has been reported, including the determination of high-resolution X-ray structures of flavodoxins from Clostridium MP (Andersen et al., 1972; Burnett et al., 1974) and Desulfovibrio vulgaris (Watenpaugh et al., 1972,1973). In this Letter we present preliminary crystallographic data on flavodoxin from $A$. nidulans (sometimes called phytoflavin), and consider some of the distinctive properties of this flavodoxin which suggest that structure analysis may provide results of significance for the biochemistry of flavoproteins.

Purification of the protein has been described earlier (Smillie, 1963,1965; Smillie \& Entsch, 1971; Bothe et al., 1971). We have crystallized $A$. nidulans flavodoxin $\dagger$ from ammonium sulfate $(2 \cdot 3$ to $2.5 \mathrm{M})$ or from $\mathrm{Na} / \mathrm{K}$ phosphate at $\mathrm{pH} 6.8$. The crystals are prisms elongated in the $a$ direction, and tend to cluster in rosettes. However, by slow growth from solutions of the semiquinone form, we can obtain crystals of adequate thickness for diffraction studies. The $m m m$ diffraction symmetry and systematic absences along all axes lead to assignment of space group $P 2_{1} 2_{1} 2_{1}$; the cell dimensions measured on a diffractometer are: $a=57.08 \AA, b=69.24 \AA$, and $c=45.55 \AA$. $A$ photograph of the $h k 0$ zone, showing reflections corresponding to Bragg spacings as small as $\mathbf{1 . 8 3} \AA$, is reproduced in Plate $\mathrm{I}$. The crystal density has not been determined, but assuming a molecular weight of 20,000 (see below), the volume per dalton is $2 \cdot 25 \AA^{3}$ for one molecule per asymmetric unit. With $\bar{v}=0 \cdot 75$, two such molecules 
per asymmetric unit would exceed the volume of the unit cell. Even if the molecular weight and $\bar{v}$ were 16,000 and $0 \cdot 70$, respectively, the volume fraction of solvent for two molecules per asymmetric unit would be only $17.4 \%$, a highly improbable value (Matthews, 1968).

Intensities from oxidized crystals have been measured to a resolution of $2 \cdot 0 \AA$. We intend to use $A$. nidulans flavodoxin to test the application of vector search methods (Nordman, 1972) to protein structure analysis, employing vector sets generated from atomic positions common to both Clostridium $M P$ and $D$. vulgaris flavodoxins. At the same time we are undertaking the preparation of heavy-atom derivatives. $\mathrm{Sm}^{3+}$ was expected to provide a derivative, as it had been used in determination of the other flavodoxin structures (Andersen et al., 1972; Watenpaugh et al., 1972). To our dismay, $\mathrm{Sm}^{3+}$ and the other lanthanides tested dissolved crystals of $A$. nidulans flavodoxin. Alternative approaches to the attachment of heavy atoms, including the use of cross-linked crystals (Quiocho \& Richards, 1964), are being explored.

The molecular weight of $A$. nidulans flavodoxin has been the subject of some disagreement. Smillie \& Entsch (1971) suggested a value of approximately 20,000 from amino acid analysis, gel filtration, and flavin mononucleotide content, whereas Bothe et al. (1971) arrived at a molecular weight of 16,000 from sedimentation and diffusion measurements. We have made another estimate of the molecular weight by sodium dodecyl sulfate-polyacrylamide gel electrophoresis (Weber et al., 1972). The molecular weight determined by this technique, using Clostridium MP flavodoxin, myoglobin, trypsin and chymotrypsinogen as standards, was between 19,000 and 19,500. Assuming the validity of the higher molecular weight estimates, the chain of $A$. nidulans flavodoxin will include 25 to 30 more residues than Clostridium $M P$ flavodoxin. Several other flavodoxins possess polypeptide chains significantly longer than those of Clostridium MP (138 residues) or D. vulgaris (148 residues) (Fox et al., 1972). In view of the similarity of the folding of flavodoxins and several pyridine nucleotide dehydrogenases (Rossmann et al., 1974), it will be interesting to determine the location of the additional residues in the higher molecular weight species. Although the extra amino acids may be distributed along the chain, it is conceivable that a new segment of secondary structure occurs in the larger flavodoxins $\dagger$.

Flavodoxins have been classified according to their ability to bind flavin analogs. Both Peptostraptococcus elsdenii and Clostridium MP flavodoxins fail to bind flavins unless the phosphate group is present (Mayhew, 1971b), but D. vulgaris, A. vinelandii, and certain other flavodoxins interact strongly with riboflavin $\left(K_{\mathrm{a}} \cong 10^{6} \mathrm{M}^{-1}\right)$. A. nidulans flavodoxin belongs to the latter family of flavodoxins (Fig. 1). Perturbations of the riboflavin spectrum, which result from binding to apoflavodoxin, have been utilized to calculate a $K_{\mathrm{a}}$ for riboflavin of $2.0 \pm 0.5 \times 10^{6} \mathrm{M}^{-1}$. A. nidulans flavodoxin thus affords us the opportunity to compare the structures of the riboflavin protein and the flavin mononucleotide protein.

Prior to the determination of the structures of $D$. vulgaris and Clostridium $M P$ flavodoxins, dissimilarities in the optical and circular dichroism spectra of flavodoxins derived from different organisms (Edmondson \& Tollin, 1971; D'Anna \& Tollin, 1972) had suggested that the arrangement of the active center of flavodoxins was not absolutely conserved during evolution. Comparison of the three-dimensional structures of $D$. vulgaris and Clostridium $M P$ flavodoxins has verified this interpreta-

$\dagger \operatorname{Dr}$ K. T. Yasunobu and co-workers at the University of Hawail have begun amino aoid sequence analysis of $A$. nidulans flavodoxin. 


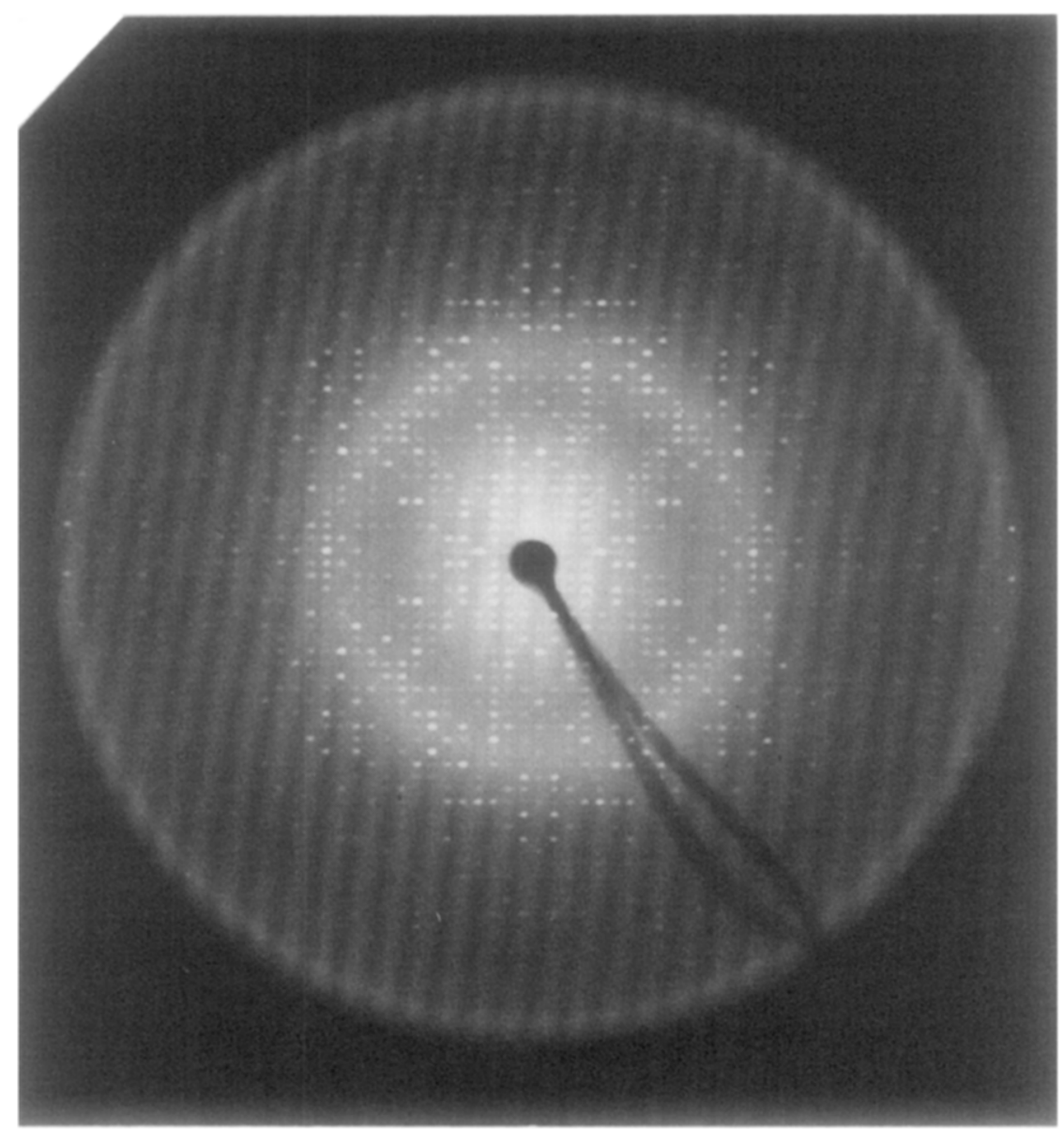

PLATE 1. A precession photograph of the $h k 0$ zone; precession angle $=25^{\circ}$. The crystal of widulue flavodoxin was mounted in a quartz capillary with the $\alpha$ axis parallel to the spindle. 


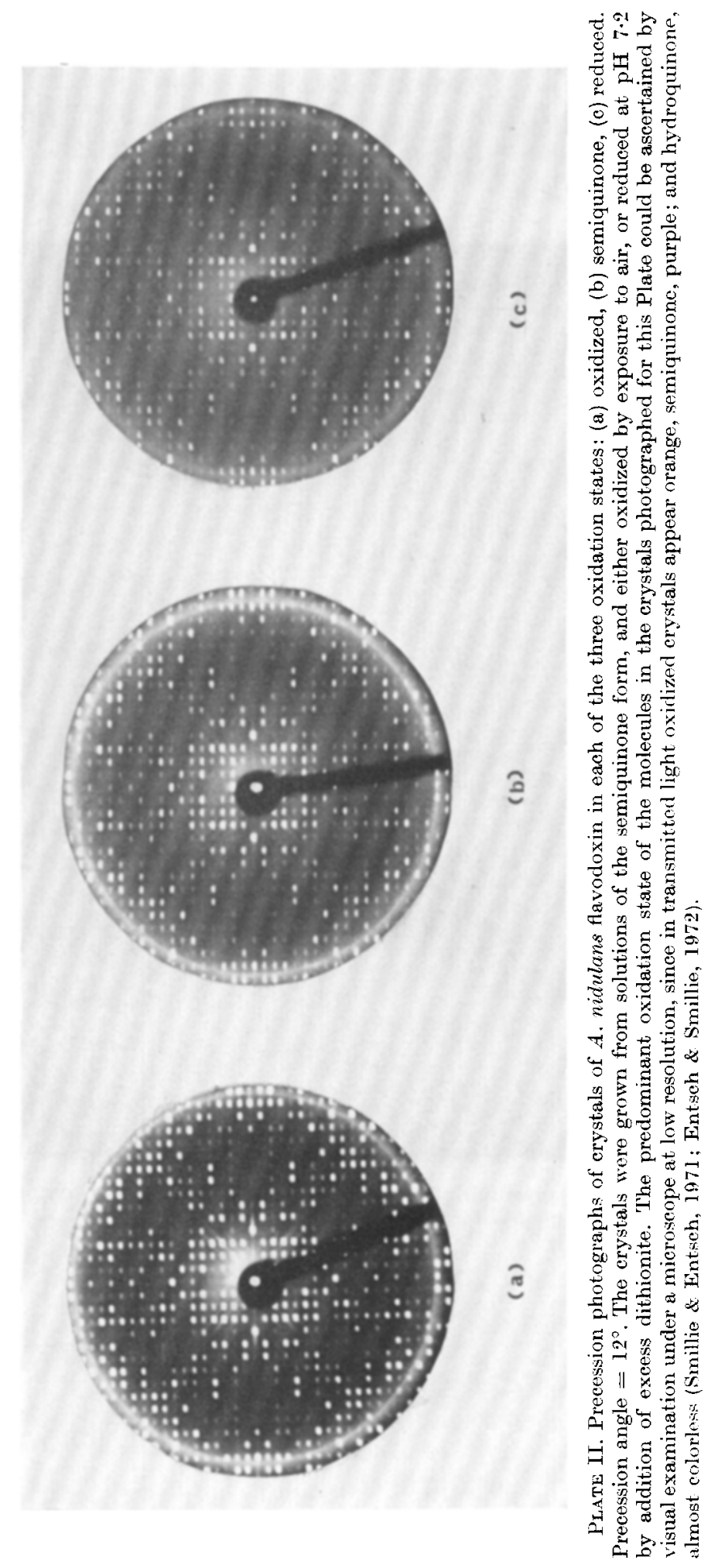




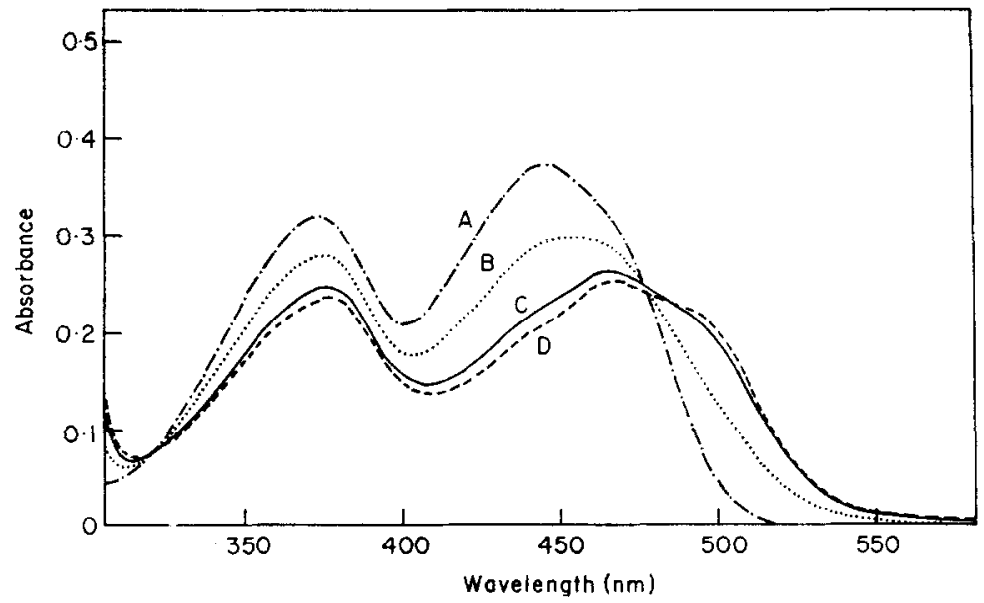

FIG. 1. Changes in the absorption spectrum of riboflavin upon addition of $A$. nidulans apoprotein. Portions of a solution of $1.0 \mathrm{~mm}$-apoflavodoxin in $0.20 \mathrm{M}$-potassium phosphate buffer, pH $7 \cdot 3$, containing $1 \mathrm{~mm}-E D T A$ were added to $1.20 \mathrm{ml}$ of a solution of riboflavin in $50 \mathrm{~mm}$ phosphate, 30 mM-EDTA. Curve A, 30.5 mu-riboflavin; curves B, C and D, spectra after addition of 20,40 and $60 \mu \mathrm{l}$ of apoprotein. For curve D, $97 \%$ of the riboflavin is complexed with protein. The temperature was $25^{\circ} \mathrm{C}$.

tion; different amino acid residues surround the isoalloxazine ring in these two flavodoxins (Burnett et al., 1974; Watenpaugh et al., 1973). The visible spectrum of oxidized $A$. nidulans flavodoxin cannot be superimposed on the spectra of either $D$. vulgaris or Clostridium MP flavodoxins. In the $A$. nidulans protein, the long-wavelength absorption maximum appears at $466 \mathrm{~nm}$, with $\varepsilon=9000 \mathrm{M}^{-1} \mathrm{~cm}^{-1}$ (Smillie \& Entsch, 1971); the corresponding maxima for Clostridium $M P$ and D. vulgaris flavodoxins occur at $445 \mathrm{~nm}$ and $456 \mathrm{~nm}$, respectively, with larger molar extinctions (Mayhew, 1971a; Dubourdieu \& LeGall, 1970). Furthermore, the spectrum of the fully reduced (hydroquinone) form of $A$. nidulans flavodoxin is distinctive. The lowest energy absorption maximum appears at shorter wavelengths in $A$. nidulans $\left(\lambda_{\max }\right.$ $=360 \mathrm{~nm}$ ) than in Clostridium $M P$ flavodoxin $\left(\lambda_{\max }=367 \mathrm{~nm}\right)$ and the pronounced shoulder, which occurs at $450 \mathrm{~nm}$ in the spectrum of reduced Clostridium $M P$ flavodoxin, is absent from the spectrum of reduced $A$. nidulans flavodoxin (Ghisla et al., 1974; Entsch \& Smillie, 1972). These spectral differences lead us to anticipate that the flavin environment in $A$. nidulans flavodoxin may be unlike that in either of the known structures.

In crystals of Clostridium MP flavodoxin, one-electron reduction of the proteinbound flavin mononucleotide is accompanied by large changes in the diffracted intensities (Ludwig et al., 1969), althongh nuclear magnetic resonance spectroscopy and $\mathrm{X}$-ray structure analysis both demonstrate that the conformation changes resulting from reduction are small (Ludwig et al., 1974; James et al., 1973). Moderateresolution diffraction patterns of crystuls of $A$. nidulans flavodoxin, on the other hand, show little if any change as the flavin is progressively reduced (Plate II). Comparison of the three oxidation states, which may suggest how combination with apoflavodoxin produces shifts in the redox potentials of flavin mononucleotide (Draper \& Ingraham, 1968; Mayhew, 1971a; Van Lin \& Bothe, 1972), should be enormously simplified by the close isomorphism. 
This research was supported by National Institutes of Health grants GM16429 and GM15259, by a Career Development Award (K4-GM-6611) to one of us (M. L. L.), and by training grant (GM00187) from the National Institutes of Health to the Department of Biological Chemistry.

Biophysios Research Division

University of Michigan

Department of Biological Chemistry

University of Michigan Medical School

Department of Chemistry

University of Michigan

Ann Arbor, Mich. 48105, U.S.A.

Chemistry Division

Argonne National Laboratory

Argonne, Ill., U.S.A.
WARD W. SMITH

BarRIE ENTSCH

Martha L. Ludwig

C. E. Nordman

Henry L. Crespi

\section{REFERENCES}

Andersen, R. D., Apgar, P. A., Burnett, R. M., Darling, G. D., LeQuesne, M. E., Mayhew, S. G. \& Ludwig, M. L. (1972). Proc. Nat. Acad. Sci., U.S.A. 69, 3189-3191.

Bothe, H., Hemmerich, P. \& Sund, H. (1971). In Flavins and Flavoproteins (Kamin, H., ed.), pp. 211-226, University Park Press, Baltimore.

Burnett, R. M., Darling, G. D., Kendall, D. S., LeQuesne, M. E., Mayhew, S. G., Smith, W. W. \& Ludwig, M. L. (1974). J. Biol. Chem. 249, 4383-4392.

D'Anna, J. A. \& Tollin, G. (1972). Biochemistry, 11, 1073-1080.

Draper, R. D. \& Ingraham, L. L. (1968). Arch. Biochem. Biophys. 125, 802-808.

Dubourdieu, M. \& LeGall, J. (1970). Biochem. Biophys. Res. Commun. 38, 965-972.

Edmondson, D. E. \& Tollin, G. (1971). Biochemistry, 10, 113-124.

Entsch, B. \& Smillie, R. M. (1972). Arch. Biochem. Biophys. 151, 378-386.

Fox, J. L., Smith, S. S. \& Brown, J. R. (1972). Z. Naturforsch. 27b, 1096-1100.

Ghisla, S., Massey, V., Lhoste, J.-M. \& Mayhew, S. G. (1974). Biochemistry, 13, 589-597.

James, T. L., Ludwig, M. L. \& Cohn, M. (1973). Proc. Nat. Acad. Sci., U.S.A. 70, 32923295 .

Ludwig, M. L., Andorson, R. D., Mayhow, S. G. \& Massoy, V. (1969). J. Biol. Chem. 244, $6047-6048$.

Ludwig, M. L., Burnett, R. M., Darling, G. D., Jordan, S. R., Kendall, D. S. \& Smith, W. W. (1975). In 4th Steenbock Symposinm, Madison Wisc. (Sundaralingam, M. \& Rao, S. T., eds), in the press,

Matthews, B. (1968). J. Mol. Biol. 33, 491-497.

Mayhew, S. G. (1971 a). Biochim. Biophys. Acta, 235, 276-288.

Mayhew, S. G. (1971b). Biochim. Biophys. Acta, 235, 289-302.

Nordman, C. E. (1972). Acta Crystallogr. Sect. A, 28, 134-143.

Quiocho, F. \& Richards, F. M. (1964). Proc. Nat. Acad. Sci., U.S.A. 52, 833-839.

Rossmann, M. G., Moras, D. \& Olsen, K. W. (1974). Nature (London), 250, 194-199.

Smillie, R. M. (1963). Plant Physiology Suppl. 38, XXVIII-XXIX.

Smillie, R. M. (1965). Biochem. Biophys. Res. Commun. 20, 621-629.

Smillie, R. M. \& Entsch, B. (1971). Methods in Enzymology, 23, 504-514.

Van Lin, B. \& Bothe, H. (1972). Arch. Microbiol. 82, 155-172.

Watenpaugh, K. D., Sieker, L. C., Jensen, L. H., LeGall, J. \& Dubourdieu, M. (1972). Proc. Nat. Acad. Sci., U.S.A. 69, $3185 \div 3188$.

Watenpaugh, K. D., Sieker, L. C. \& Jensen, L. H. (1973). Proc. Nat. Acad. Sci., U.S.A. 70, 3857-3860.

Weber, K., Pringle, J. R. \& Osborn, M. (1972). Methods in Enzymology, 26, 3-27.

Yoch, D. C. \& Valentine, R. C. (1972). Annu. Rev. Microbiol. 26, 139-157. 